Journal of Telenursing (JOTING)

Volume 1, Nomor 2, Desember 2019

e-ISSN: 2684-8988

p-ISSN: 2684-8996

DOI: https://doi.org/10.31539/joting.v1i2.965

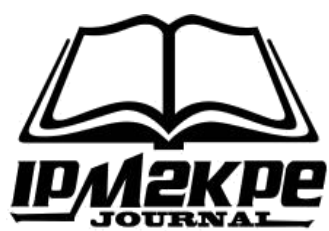

\title{
EFEK PAKET "TABAHANMIL" TERHADAP PENGETAHUAN, SIKAP DAN KETRAMPILAN IBU HAMIL DALAM MENCEGAH PERDARAHAN
}

\author{
Eko Riyanti ${ }^{1}$, Irna Nursanti ${ }^{2}$, Natsir Hugroho ${ }^{3}$ \\ Akademi Keperawatan Pemerintah Kabupaten Purworejo ${ }^{1}$ \\ Universitas Muhammadiyah Jakarta ${ }^{2,3}$ \\ riyantieko49@yahoo.co.id ${ }^{1}$
}

\begin{abstract}
ABSTRAK
Tujuan penelitian adalah mengetahui efek pemberian paket tanda bahaya perdarahan ibu hamil (tabahanmil) terhadap pengetahuan, sikap dan ketrampilan ibu hamil dalam mencegah perdarahan di Kecamatan Bayan Kabupaten Purworejo. Jenis penelitian kuantitatif dengan desain penelitian quasi eksperimental, rancangan pretest-posttest with control group design. Hasil analisis bivariat diketahui bahwa pada kelompok intervensi sesudah diberikan paket tabahanmil berpengaruh secara bermakna dibandingkan dengan kelompok kontrol yang tidak diberikan paket tabahanmil pada pengetahuan, sikap, dan ketrampilan yang masing-masing mempunyai $p$ value $=0,000$ lebih kecil dari 0,05. Simpulan, ada perbedaan yang signifikan dari nilai rata-rata pengetahuan, sikap, dan ketrampilan ibu hamil dalam mencegah pendarahan pada kelompok intervensi dan kelompok kontrol.
\end{abstract}

Kata Kunci: Ibu Hamil, Keterampilan, Mencegah Perdarahan, Pengetahuan, Sikap

\section{ABSTRACT}

The purpose of this study was to determine the effect of the package of warning signs of bleeding pregnant women (tabahanmil) on the knowledge, attitudes and skills of pregnant women in preventing bleeding in Bayan District, Purworejo Regency. The type of quantitative research with Quasi experimental research design, pretest-posttest with control group design. The results of bivariate analysis found that the intervention group after being given a tabahanmil package significantly affected compared to the control group that was not given a tabahanmil package on knowledge, attitudes, and skills, each of which has a p value $=0,000$ less than 0.05. Conclusion, there is a significant difference from the average value of knowledge, attitudes, and skills of pregnant women in preventing bleeding in the intervention group and the control group.

Keywords: Pregnant Women, Skills, Preventing Bleeding, Knowledge, Attitudes 


\section{PENDAHULUAN}

Sustainabel Development Goals (SDG's) adalah suatu upaya peningkatan status derajat kesehatan ibu serta anak yang menjadi prioritas dalam program pembangunan kesehatan di Indonesia serta merupakan tujuan pada sektor kesehatan. Mengurangi Angka Kematian Ibu (AKI) hingga di bawah 70 per 100.000 kelahiran hidup merupakan goal dari sektor kesehatan (Depkes, 2016).

Sebagai salah satu indikator pembangunan kesehatan dalam RPJMN 2015-2019 dan SDG's adalah AKI dimana terjadi peningkatan dari 228per 100.000 kelahiran hidup pada tahun 2007 menjadi 359 tahun 2012 (SDKI, 2017). AKI di Jawa Tengah sedikit mengalami penurunan pada tahun 2015 dengan jumlah 111,16 kasusdan menurun pada tahun 2017 menjadi 88,05 per 100.000 kelahiran hidup (Dinkes Jateng, 2017).

Angka kematian ibu (AKI) pada melahirkan masih tinggi, hal ini merupakan salah satu contoh masalah dari beberapa permasalahan kesehatan yang signifikan di Indonesia (Angraini et al., 2011). Kematian ibu menurut definisi WHO adalah kematian selama kehamilan atau dalam periode 42 hari setelah berakhirnya kehamilan, akibat semua sebab yang terkait dengan atau diperberat oleh kehamilan atau penanganannya tetapi bukan disebabkan oleh kecelakaan/cedera. Angka Kematian Ibu (AKI) merupakan salah satu indikator yang peka dalam menggambarkan kesejahteraan masyarakat di suatu negara (Kemenkes RI, 2014).

Penyebab AKI secara tidak langsung dikarenakan tidak mengenali tanda bahaya atau faktor resiko ibu hamil, keterlambatan kemampuan mengambil keputusan, serta tidak memiliki akses pelayanan kesehatan berkualitas terutama kegawatdaruratan tepat waktu, selain disebabkan 4 kriteria'terlalu': terlalu tua, terlalu muda, anak terlalu banyak dan paritas terlalu dekat (Dinkes Jateng, 2017). Kematian ibu 80\% disebabkan untuk memperoleh informasi baru terkait lingkungan kerja hingga proses bekerja di Rumah Sakit. Orientasi yang diberikan dapat berupa konvensional maupun nonkonvensional. Metode non-konvensional salah satunya berupa orientasi menggunakan E-learning. E-learning adalah suatu pembelajaran yang berbasis teknologi informasi. Hal ini akan memudahkan perawat baru untuk menerima orientasi dengan mudah.

Menurut Notoatmodjo (2010) bahwa pendidikan kesehatan dalam jangka waktu pendek dapat menghasilkan perubahan dan peningkatan pengetahuan individu, kelompok dan masyarakat. Perbedaan sikap kelompok kontrol dan intervensi pada saat pretest-posttest secara signifikan lebih tinggi sesudah diberikan dibanding sebelum diberikan paket tabahanmil, sejalan dengan teori antenatal care yang menyatakan bahwa pengatahuan ibu akan semakin baik bila ibu rajin memeriksakan kehamilannya secara berkala dan mendapatkan edukasi dan konseling dari tenaga kesehatan dalam penambahan menu diet selama kehamilan (Padila, 2015).

Berdasarkan Survei Demografi dan Kesehatan Indonesia (SDKI) tahun 2012, AKI di Indonesia masih tinggi sebesar 359 per 100.000 kelahiran hidup. Angka tersebut sedikit menurun meskipun tidak terlalu signifikan. Target global MDGs (Millenium Development Goals) ke-5 adalah menurunkan AKI menjadi 102 per 100.000 kelahiran hidup tahun 2015. Target MDGs ke-5 tersebut diperlukan kerja keras dan kerjasama antara semua pihak untuk mencapainya. Penyebab kematian ibu selama tahun 20102013 masih tetap sama yaitu perdarahan, hipertensi dalam kehamilan, infeksi, partus lama, abortus dll (Kemenkes RI, 2014). Pada tiga bulan tahun 2015 terakhir sudah ada 115 kasus AKI dan AKB di Jawa Tengah. Dieks Karesidenan Banyumas ada 15 kasus, AKI tersebut nomor tiga tertinggi se-Jawa Tengah setelah Karesidenan Pekalongan dan 
Karesidenan Semarang (Nurdin N., 2015). Penyebab kematian ibu adalah pre-eklamsiaeklamsia (28.76\%), perdarahan (22.42\%), infeksi (3.54\%) dsb (Damayanti, 2013).

Hal ini didukung oleh penelitian yang dilakukan oleh Suratmi \& Suwardi (2017) yang menyatakan bahwa e-learning berbasis web efektif dalam meningkatkan kompetensi perawat di RS Muhammadiyah Lamongan. Simulasi menggunakan teknologi dapat membantu perawat baru meningkatkan kepercayaan diri dan pengalaman merawat pasien dalam keadaan kritis tanpa membahayakan pasien. oleh penyebab langsung obstetrik seperti perdarahan, sepsis, abortus, dan preeklamsiaeklamsia, sisanya karena penyakit yang diperberat oleh kehamilan. Perdarahan menjadi gejala komplikasi terbanyak yang dilaporkan, meningkat 3 persen padatahun 2007 menjadi 5 persen pada tahun 2017 (SDKI, 2017). Penyebab AKI di Provinsi Jawa Tengah tahun 2017 tertinggi kedua adalah perdarahan 30,37\% (Dinkes Jateng, 2017).

Abortus, kehamilan ektopik, molahidatidosa, plasenta previa, serta solusio plasenta hampir selalu menyebabkan perdarahan pada kehamilan (Bobak, 2004). AKI tahun 2013 sebanyak 7 kasus dengan penyebab perdarahan sebanyak 3 kasus, hipertensi kehamilan 2 kasus dan lain-lain 2 kasus (Dinkes Purworejo, 2013). Data survai di Dinas Kesehatan Kabupaten Purworejo, tahun 2017 jumlah AKI meningkat menjadi 16 kasus dengan penyebab perdarahan sebanyak 5 kasus(31,3 \%) (Dinkes Purworejo, 2017).

Kehamilan merupakan sebuah proses fisiologis, juga diartikan sebagai situasi krisis, saat terjadi gangguan dan perubahan peran bagi setiap anggota keluarga. Keseimbangan psikologis yang disebabkan oleh situasi dan tahap perkembangan ibu didefinisikan sebagai krisis (Hutahaean, 2013). Roy mengembangkan sebuah konsep model keperawatan dalam kerangka konsep adaptasi. Adaptasi selama proses kehamilan harus berada pada area adaptif, perilaku adaptasi sangat bervariasi. Respon maladaptive merupakan dampak yang muncul berupa koping tidak konstruktif atau efektif dimana individu mempunyai masalah adaptive (Marriner \& Alligood, 2010). Input Proses

Output

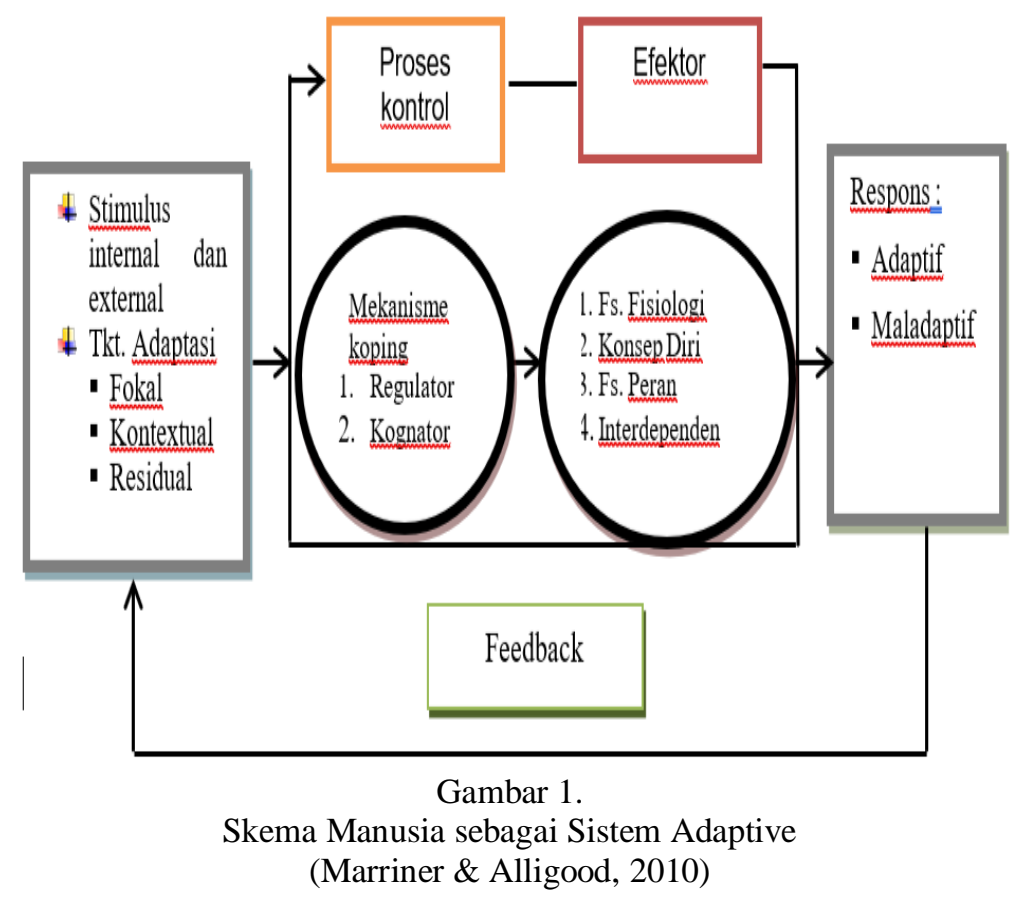


Paket tanda bahaya perdarahan ibu hamil (tabahanmil) merupakan suatu paket pendidikan kesehatan yang diberikan pada ibu hamil dalam upaya pencegahan terhadap perdarahan, diberikan dalam bentuk paket berupa ceramah dan pemberian booklet secara kombinasi. Kebaruan dari penelitian berupa bahasan materi pokok penelitian dari buku panduan Kesehatan Ibu Anak Depkes RI dengan memberikan tambahan materi secara teknis spesifik tentang pencegahan bahaya perdarahan pada ibu hamil.

Rumusan masalah penelitian ini "Bagaimana efek pemberian paket tabahanmil terhadap pengetahuan, sikap dan ketrampilan ibu hamil dalam mencegah perdarahan". Tujuan penelitian adalah diketahui efek pemberian paket Tabahanmil terhadap pengetahuan, sikap dan ketrampilan ibu hamil dalam mencegah perdarahan, teridentifikasi perbedaaan rata-rata sebelum dan sesudah pemberian paket tabahanmil padakelompok intervensi dengan kelompok kontrol.

\section{METODE PENELITIAN}

Jenis penelitian kuantitatif dengan desain penelitian quasi eksperimental, menggunakan rancangan pretest - posttest with control group design. Responden dibagi menjadi dua kelompok: kelompok intervensi yang mendapatkan paket tabahanmil37 respondendan kelompok kontrol yang tidak pendapatkan paket tabahanmil 37 responden. Tehnik pengambilan sampel dengan purposive sampling dengan kriteria inklusi: ibu hamil trimester I dan II di wilayah Puskesmas Bayan, usia 17 - 45tahun, mampu baca tulis dan berbahasa Indonesia serta kriteria ekslusi: ibu hamil dengan gangguan mental, tidak bersedia menjadi responden.

Instrumen dalam penelitian menggunakan kuesioner, data diperoleh dari pertanyaan tentang karateristik responden dengan pertanyaan item 1 sampai 6 terdiri dari: usia, tingkat pendidikan, pekerjaan, agama, suku dan paritas. Kuesioner didapat langsung dari responden yang bersifat tertutup terdiri dari pengetahuan, sikap dan ketrampilan ibu hamil.

Uji validitas telah dilakukan pada 30 ibu hamil yang bukan responden penelitian,pertanyaan dinyatakan valid dengan nilai $>$ dari $r$ tabel $=0,361$. Nilai uji reliabilitas pertanyaan bila> $r$ tabel. Hasil nilai Alfa Cronbachs pengetahuan, sikap ketrampilan lebih dari 0,70 sehingga pertanyaan reliabel. Jumlah pertanyaan pengetahuan 12 butir, sikap 7 butir dan keterampilan 8 butir.

Pelaksanaan penelitian dilakukan setelah mendapatkan lolos uji etik, memberikan informasi tentang penelitian dan persetujuan responden, kelompok intervensi didahului mengajukan pretest dengan mengisi kuesionar. Setelah pretest dilanjutkan memberikan edukasi paket tabahanmil dengan metode ceramah dan pemberian Booklet untuk dibawa pulang, selanjutnya melakukan kontrak satu minggu kemudian untuk posttest. Identitas dan data yang diberikan responden dijamin kerahasiaanya. Pada kelompok kontrol kegiatan pretest tanpa diikuti pemberian paket tabahanmil, satu minggu kemudian disepakati untuk melakukan posttest. Pada kelompok kontrol diberikan paket tabahanmil setelah posttest. 


\section{HASIL PENELITIAN}

Analisis univariat dalam penelitian ini menjelaskan karakteristik responden kelompok kontrol maupun kelompok intervensi berdasarkan usia, pendidikan, pekerjaan, agama, suku, dan frekuensi kehamilan.

Tabel. 1

Karakteristik Responden

\begin{tabular}{|c|c|c|c|c|c|}
\hline \multirow{2}{*}{$\begin{array}{l}\text { Deskripsi } \\
\text { Karakteristik } \\
\text { Responden ibu } \\
\text { Hamil }(\mathrm{n}=74)\end{array}$} & \multicolumn{2}{|c|}{ Kelompok Kontrol $(n=37)$} & \multicolumn{2}{|c|}{ Kelompok Intervensi(n=37) } & \multirow[b]{2}{*}{$\begin{array}{l}p \text {-value uji } \\
\text { homogenitas }\end{array}$} \\
\hline & $\begin{array}{l}\text { Frekuensi } \\
\text { (Orang) }\end{array}$ & $\begin{array}{l}\text { Persentase } \\
(\%)\end{array}$ & $\begin{array}{l}\text { Frekuensi } \\
\text { (Orang) }\end{array}$ & $\begin{array}{l}\text { Persentase } \\
(\%)\end{array}$ & \\
\hline \multicolumn{6}{|l|}{ Usia: } \\
\hline Mean & 26,73 & & 28,30 & & \multirow{5}{*}{0,003} \\
\hline Modus & & & & & \\
\hline Median & & & 28 & & \\
\hline SD & 4,46 & & 2,60 & & \\
\hline Min-max & $17-37$ & & $24-34$ & & \\
\hline \multicolumn{5}{|l|}{ Pendidikan: } & \multirow{3}{*}{0,000} \\
\hline Rendah & 35 & 94,6 & 25 & 67,6 & \\
\hline Tinggi & 2 & 5,4 & 12 & 32,4 & \\
\hline \multicolumn{5}{|l|}{ Pekerjaan: } & \multirow[t]{3}{*}{0,000} \\
\hline Tidak bekerja & 34 & 91,9 & 9 & 24,3 & \\
\hline Bekerja & 3 & 8,1 & 28 & 75,7 & \\
\hline \multicolumn{6}{|l|}{ Agama: } \\
\hline Muslim & 37 & 100 & 37 & 100 & \multirow[t]{2}{*}{ - } \\
\hline NonMuslim & 0 & 0 & 0 & 0 & \\
\hline \multicolumn{6}{|l|}{ Suku: } \\
\hline Non Jawa & 0 & 0 & 0 & 0 & \multirow[t]{2}{*}{-} \\
\hline Jawa & 37 & 100 & 37 & 100 & \\
\hline \multicolumn{5}{|l|}{ Paritas: } & \multirow[t]{3}{*}{10,000} \\
\hline Multipara & 15 & 40,5 & 34 & 91,9 & \\
\hline Primipara & 22 & 59,5 & 3 & 8,1 & \\
\hline
\end{tabular}

Sumber: Data primer diolah, 2019.

Berdasarkan tabel 1 memperlihatkan dari 74 responden, usia rata-rata kelompok kontrol adalah 26,73, sedangkan kelompok intervensi adalah 28,30. Tingkat pendidikan responden kelompok kontrol terbanyak adalah pendidikan rendah sebanyak 35 orang $(94,6 \%)$, sedangkan kelompok intervensi terbanyak adalah pendidikan rendah sebanyak 25 orang $(67,6 \%)$. Responden kelompok kontrol tidak bekerja sebanyak 34 orang (91,9\%), sedangkan kelompok intervensi sebanyak 28 orang bekerja (75,7). Semua responden kelompok kontrol dan kelompok intervensi beragama muslim masing-masing sebanyak 37 orang $(100 \%)$ dan semua responden kelompok kontrol dan kelompok intervensi berasa dari suku Jawa sebanyak 37 orang (100\%), kelompok kontrol dengan kehamilan pertama kali atau primigravida sebanyak 22 orang $(59,5 \%)$, sedangkanpada kelompok intervensi dengankehamilan multigravida kehamilan multigravida sebanyak 34 orang $(91,9 \%)$. 
Tabel. 2

Hasil Uji Beda Pengetahuan, Sikap, dan Ketrampilan Kelompok Kontrol dan Intervensi

\begin{tabular}{|c|c|c|c|c|c|c|c|c|c|}
\hline \multirow[b]{2}{*}{ Variabel } & \multirow[b]{2}{*}{ Intervensi } & \multicolumn{3}{|c|}{ Kelompok Intervensi(n=37) } & \multicolumn{5}{|c|}{ Kelompok Kontrol(n=37) } \\
\hline & & Mean & SD & $\begin{array}{l}\text { Median } \\
\text { (min-max) }\end{array}$ & $\begin{array}{c}p \\
\text { value }\end{array}$ & Mean & SD & $\begin{array}{c}\text { Median } \\
(\text { min- } \\
\text { max })\end{array}$ & $\begin{array}{c}p \\
\text { value }\end{array}$ \\
\hline \multicolumn{10}{|l|}{ Kemampuan } \\
\hline \multirow[t]{2}{*}{ Pengetahuan } & Sebelum & 6,32 & 1,156 & $7(4-6)$ & 0,000 & 2,46 & 0,931 & $2(1-4)$ & 0,000 \\
\hline & Sesudah & 9,38 & 1,277 & $9(6-11)$ & & 4,92 & 1,362 & $4(3-8)$ & \\
\hline \multirow[t]{2}{*}{ Sikap } & Sebelum & 19,27 & 1,836 & $19(17-23)$ & 0,000 & 13,24 & 2,385 & $\begin{array}{c}13(10- \\
20)\end{array}$ & 0,000 \\
\hline & Sesudah & 24,35 & 2,058 & $24(20-28)$ & & 16,35 & 2,383 & $\begin{array}{c}16(12- \\
23)\end{array}$ & \\
\hline \multirow[t]{2}{*}{ Ketrampilan } & Sebelum & 4,89 & 1,100 & $4(3-7)$ & 0,000 & 1,97 & ,726 & $2(1-3)$ & 0,000 \\
\hline & Sesudah & 6,43 & 0,929 & $7(4-8)$ & & 3,76 & ,925 & $4(2-6)$ & \\
\hline
\end{tabular}

Sumber: Data primer diolah, 2019

Analisis bivariat untuk mengetahui ada atau tidaknya perbedaan pengetahuan, sikap, dan keterampilan sebelum dan sesudah diberikan intervensi paket tabahanmil.Uji prasyarat dilakukan uji normalitas menggunakan shapiro wilk dan uji homogenitas.

Berdasarkan hasil pengujian normalitas dan homogenitas pada tabel 2, bahwa nilai $p$-value dari variabel pengetahuan, sikap dan ketrampilan responden kelompok intervensi dan kelompok kontrol pada saat pretest dan posttest yang seluruhnya lebih kecil dari taraf signifikansi menunjukkan bahwa data dinyatakan tidakberdistribusi normal. Nilai $p$ uji homogenitas pengetahuan, sikap dan ketrampilan seluruhnya lebih besar dari taraf signifikansi $(\alpha)=0,05$. berarti bahwa data dinyatakan homogen. Alat uji yang digunakan dalam analisis bivariat ini adalah uji Wilcoxon.

Tabel 2 dapat diketahui bahwa pada kelompok intervensi sesudah paket tabahanmil berpengaruh secara bermakna dibandingkan dengan kelompok kontrol yang tidak diberikan intervensi tabahanmil pada pengetahuan sikap, dan ketrampilan yang masing-masing mempunyai $p$ value $=0,000$ yang lebih kecil dari 0,05, maka Ho ditolak dan Ha diterima atau hipotesis dalam penelitian ini terbukti.

\section{PEMBAHASAN}

Karateristik responden berdasarkan hasil penelitian dapat diketahui bahwa usia rata-rata kelompok kontrol adalah 26,73 tahun, sedangkan usia rata-rata kelompok intervensi adalah 28,30 tahun, didukung oleh hasil penelitian dari Haryanti (2008) menemukan bahwasebagian besar yaitu sebanyak 8 orang $(50 \%)$ ibu hamil primigravida mempunyai umur berkisar antara 25-30 tahun. Usia tersebut berarti tergolong dalam kelompok usia produktif.

Kelompok umur produktif kemampuan intelektual berfungsi dalam menganalisa suatu informasi kesehatan yang diterimanya, masa usia produktif membuat ibu memiliki kematangan rasional dan psikomotor yang baik, dimana bermanfaat ketika ibu mendapat pendidikan kesehatan akan segera mengetahui dan memahami tentang manfaat dan pentingnya mengetahui tanda bahaya kehamilan dan persalinan. 
Penelitian ini memperlihatkan responden kelompok kontrol telah menempuh pendidikan terakhir yang termasuk kategori rendah (SD-SMA), sebanyak 35 orang (94,6\%), sedangkan kelompok intervensi juga pendidikan kategori rendah (SMA) sebanyak 25 orang $(67,6 \%)$. Tingkat pendidikan tersebut menunjukan bahwa responden kelompok kontrolmaupun intervensi telah memiliki tingkat pendidikan menengah. Tingkat pendidikan berhubungan dengan kemampuan responden memahami informasi tentang kesehatan yang diterima. Semakin tinggi tingkat pendidikan seseorang, maka kemampuannya memahami informasi kesehatan semakin baik (Astuti et al., 2012). Peneliti berpendapat makin tinggi tingkat pendidikan maka akan semakin mudah menerima informasi, sehingga semakin banyak pengetahuan yang diterimanya.

Hasil penelitian menunjukkan sebagian besar kelompok kontrol tidak bekerja, sebanyak 34 orang $(91,9 \%)$, sesuai dengan pendapat Friedman et al., (2010) bahwa perempuan dipandang sebagai pengurus rumah tangga dan cenderung lebih peduli terhadap perubahan status kesehatan dan mencari pengobatan serta berperan sebagai pemimpin kesehatan keluarga, pada kelompok intervensi yang sebagian besar mempunyai pekerjaan yaitu sebanyak 28 orang $(75,7 \%)$. Wanita yang sibuk bekerja hanya memiliki sedikit waktu untuk memperoleh informasi sehingga pengetahuan yang mereka peroleh kurang (Notoatmodjo, 2010).

Penelitian ini memperlihatkan mayoritas kelompok kontrol maupun kelompok intervensidalam penelitian ini memeluk agama Islam sebanyak 37 orang (100\%), didukung data rincian persentase penduduk berdasarkan agama di kecamatan Bayan, kabupaten Purworejo tahun 2017 sebanyak 99,39 persen penduduk beragama Islam, demikian juga kelompok kontrol maupun kelompok intervensi berasal dari suku Jawa, sebanyak 37 orang (100\%), sesuai dengan data sensus penduduk dari BPS terbaru pada tahun 2010 bahwa suku Jawa adalah suku terbesar sebanyak 40,05 \%.

Hasil penelitian responden paritas kelompok kontrol primipara sebanyak 22 orang (59,5\%), sedangkan kelompok intervensi terbanyak multipara 34 orang $(91,9 \%)$. Perawatan dan pendidikan kesehatan direncanakan untuk membantu seorang ibu hamil terutama primigravida guna mempersiapkan dirinya secara jasmani dan rohani.

Hasil analisis bivariat, perbedaan pengetahuan kelompok kontrol dan intervensi pada saat pretest-posttest, secara signifikan lebih tinggi sesudah diberikan dibanding sebelum diberikan paket tabahanmil, sejalan dengan penelitian dari Kourorian et al., (2014) yang menyimpulkan bahwa dalam meningkatkan pengetahuan, sikap, dan tindakan individu diperlukan pemberian intervensi yang positif. Menurut Notoatmodjo (2010) bahwa pendidikan kesehatan dalam jangka waktu pendek dapat menghasilkan perubahan dan peningkatan pengetahuan individu, kelompok dan masyarakat. Perbedaan sikap kelompok kontrol dan intervensi pada saat pretest-posttest secara signifikan lebih tinggi sesudah diberikan dibanding sebelum diberikan paket tabahanmil, sejalan dengan teori antenatal care yang menyatakan bahwa pengatahuan ibu akan semakin baik bila ibu rajin memeriksakan kehamilannya secara berkala dan mendapatkan edukasi dan konseling dari tenaga kesehatan dalam penambahan menu diet selama kehamilan (Padila, 2015).

Menurut hasil penelitian dari Shanthini et al., (2017) yang menemukan bahwa ada perbedaan sikap ibu hamil sebelum dan sesudah memperoleh intervensi pada kelompok intervensi maupun kelompok kontrol. Pemberian intervensi dapat meningkatkan sikap ibu hamil dalam merawat kehamilan dan kesehatannya selama masa kehamilan, menjadi lebih baik dari sebelumnya setelah memperoleh intervensi promosi kesehatan. 
Perbedaan ketrampilan kelompok kontrol dan intervensi pada saat pretestposttestsignifikan lebih tinggi sesudah diberikan dibanding sebelum diberikan paket tanda bahaya pendarahan ibu hamil (tabahanmil), sesuai dengan hasil penelitian Hastuti et al., (2011) yang menemukan bahwa keterampilan responden mengenai antenatal care secara signifikan menjadi lebih tinggi dibanding sebelum mengikuti pelatihan kelas ibu hamil, sependapat yang diungkapkan oleh Fitriani (2013) bahwa penyuluhan kesehatan adalah penambahan kemampuan dan pengetahuan seseorang melalui tehnik praktek belajar atau instruksi dengan tujuan mengubah atau mempengaruhi perilaku manusia secara individu, kelompok maupun masyarakat.

Penelitian diharapkan mampu memberikan kontribusi pada upaya pemerintah dalam strategi operasional menangani AKI dengan mengatasi faktor resiko kematian berupa 3 Terlambat (3T) yaitu: terlambat mengenali tanda bahaya, terlambat mengambil keputusan karena pemahaman ibu dan keluarga dan terlambat merujuk ibu hamil sehingga terlambat dalam menangani perdarahan (Kemenkes RI, 2014). Penyebab kematian ibu sangat bermacam-macam tetapi penyebab terbesarnya yaitu perdarahan, hipertensi dalam kehamilan, infeksi, partus lama/macet, dan abortus (Kemenkes, 2014).

Teori adaptasi Roy dapat diterapkan pada semua sistem karena memenuhi aspek kebutuhan fisiologis, konsep diri, adaptasi dan interdependensi. Kegiatan memberikan edukasi secara terstruktur sebagai efikasi responden untuk fungsi kognitif dapat bertambah akan terbentuk motivasi dan keyakinan untuk melakukan antisipasi dan perawatan mandiri sesuai penelitian Hidayati (2014) penerapan teori adaptasi Roy menunjukkan adanya mekanisme adaptasi positif terhadap stimulus yang diterima pasien. Kesimpulan dari penelitian diketahui bahwa terdapat perbedaaan rata-rata sebelum dan sesudah pemberian paket tabahanmil pada kelompok intervensi dan kontrol baik pengetahuan, sikap dan ketrampilan dengan $p$ value $=0,00$ sehingga Ho ditolak. Hasil uji beda pada kelompok intervensi sesudah diberikan paket tabahanmil berpengaruh secara bermakna dibandingkan dengan kelompok kontrol yang tidak diberikan paket tabahanmil pada pengetahuan, sikap dan ketrampilan ibu hamil dalam mencegah pendarahan masing-masing mempunyai $p$ value $=0,000$, maka Ho ditolak atau hipotesis dalam penelitian ini terbukti.

Hasil penelitian ini diharapkan menjadi data dasar memberikan intervensi keperawatan berupa edukasi dengan mengembangkan media pembelajaran yang lebih efektif dan edukatif sehingga menambah pengetahuan aplikatif ibu hamil dan sebagai rujukan bagi pengembangan penelitian selanjutnya tentang paket tabahanmil dengan pendekatan kualitatif maupun kombinasi kuantitatif dengan kualitatif.

\section{SIMPULAN}

Simpulan dalam penelitian ini adalah ada perbedaan yang signifikan dari nilai rata-rata pengetahuan, sikap, dan ketrampilan ibu hamil dalam mencegah pendarahan pada kelompok intervensi dan kelompok kontrol.

\section{SARAN}

Saran dari peneliti agar penelitian ini dapat dijadikan data dasar untuk dilakukan penelitian lebih lanjut dengan menggunakan pendekatan penelitian kualitatif maupun kombinasi kuantitatif dengan kualitatif. 


\section{DAFTAR PUSTAKA}

Angraini, D., Susanti, D. S., Salam, N. (2011). Pengaruh Pemberian Vitamin C dan Sulfat Ferroses (SF) pada Ibu Hamil untuk Mengurangi Resiko Anemia pada Saat Persalian Menggunakan Analisis Data Berpasangan. Jurnal Matematika Murni dan Terapan

Astuti, E. W., Sulastri, S., \& Kartinah, K. (2012). Pengaruh Pendidikan Kesehatan terhadap Perubahan Pengetahuan dan Sikap Ibu Hamil dalam Mengkonsumsi Tablet Fe (Ferum) di Rumah Bersalin Sri Lumintu Surakarta. Naskah Publikasi: Universitas Muhammadiyah Surakarta

Bobak, J. Z. (2004). Maternity and Gynaecological Care. Toronto: St. Louis, Baltimore

Damayanti, N. P. (2013). Preeklamsia-Eklamsia Berjaya sebagai Penyebab Utama Kematian Ibu. https://dinkeskebumen.wordpress.com/2013/04/03/preeklamsiaeklamsia-berjaya-sebagai-penyebab-utama-kematian-ibu/

Depkes, RI. (2016). Agenda SDGs dalam Rakernas 2016. Jakarta: Departemen Kesehatan Republik Indonesia. Retrieved from http://www.depkes.go.id

Dinkes Purworejo. (2013). Profil DinKes. Kab. Purworejo

Dinkes Jawa Tengah. (2017). Profil Kesehatan Provinsi Jawa Tengah Tahun 2017 (Vol. 3511351)

Fitriani, S. (2013). Promosi Kesehatan. Yogyakarta: Graha Ilmu

Friedman, M. M., Bowden, O., \& Jones, M. (2010). Buku Ajar Keperawatan Keluarga: Riset, Teori, \& Praktik; Alih Bahasa, Achir Yani S. Hamid...[et al.]; editor edisi bahasa Indonesia, Estu Tiar, Ed. 5. Jakarta: EGC

Haryanti, H., \& Rusiana, S. (2008). Perbedaan Tingkat Pengetahuan antara Primigravida dan Multigravida tentang Tanda Bahaya Kehamilan di Puskesmas Sibela Surakarta. Fakultas Kedokteran Universitas Sebelas Maret

Hastuti, P. S., Nugroho, H. S. W., \& Usnawati, N. (2011). Efektifitas Pelatihan Kelas Ibu Hamil untuk Meningkatkan Pengetahuan, Sikap, Keterampilan dan Kunjungan Antenatal Care. Jurnal Penelitian Kesehatan Suara Forikes, 2(2), 122-133

Hidayati, R. (2014). Aplikasi Teori Adaptasi Roy pada Pasien dengan Penyakit Ginjal Tahap Akhir di RSUPN Dr. Cipto Mangunkusumo Jakarta. Universitas Indonesia

Hutahaean, S. (2013). Perawatan Antenatal. Jakarta: Salemba Medika

Kemenkes RI. (2014). Mothers Day: Situasi Kesehatan Ibu. http://www.depkes.go.id/download.php?file=download/pusdatin/infodatin/infodati n-ibu.pdf

Kourorian, Z., Azarkeivan, A., Hajibeigi, B., Oshidari, A., \& Shirkavnd, A. (2014). The Effect of Knowledge, Attitude, and Practice on the Function of Thalassemic Patients. Iranian Journal of Blood and Cancer, 6(4), 177-181

Marriner, T, A., \& Alligood, M. R. (2010). Nursing Theory and Their Work (7rded ed.). St. Louis: Mosby

Notoatmodjo, S. (2010). Ilmu Perilaku Kesehatan. Jakarta: Rineka Cipta

Nurdin, N. (2015). Angka Kematian Ibu Tinggi, Ganjar Mengaku Galau. http://regional.kompas.com/read/2015/06/11/14270901/Angka.Kematian.Ibu.Ting gi.Ganjar.Mengaku.Galau

Padila, P. (2015). Asuhan Keperawatan Maternitas 1. Yogyakarta: Nuha Medika

SDKI. (2017). 2017 Survei Demografi dan Kependudukan 
Shanthini, R., Priya, Garla, B. K., Muthu, K. R., \& Taranath, M. (2017). Effectiveness of Anticipatory Guidance on the Knowledge and Attitude of Pregnant Women Attending Government Hospital, Thirumangalam, Madurai. Journal of Advanced Oral Research, 8(1\&2), 8-13

Suratmi, S., \& Suwardi, S. (2017). Efektifitas E-Learning Berbasis Web sebagai Pendukung In House Training dalam Meningkatkan Kompetensi Perawat di Rumah Sakit Muhammadiyah Lamongan. Medical Technology and Public Health Journal (MTPH Journal), 1(2), 109-117 